Michael Guggenheim

\title{
How to use ANT in inventive ways so that its critique will not run out of steam?
}

To appear in: Anders Blok, Ignacio Farias, Celia Roberts (eds.): ANT Companion. London, Routledge 2019.

"Critique behaves like blasé tourists who would like to reach the most virgin territories without difficulty, but only if they don't come across any other tourists." (Latour 2013, 85)

It is one of the recurring tropes of ANT to portray itself as nothing but an empiricist endeavour to understand the socio-material word, abstaining from the blasé practices of critique. When I was drawn to ANT as a student in the 1990s, I became quickly puzzled by the strong claims that ANT cannot be delineated, that it is supposed to be a method, or a "sensibility" but not a theory, while at the same time the proponents of ANT voiced very strong critiques of other approaches (see e.g. Law 2008). Reading ANT texts, it is hard not to conclude that ANT itself is a critical theory of sorts, full of critical judgments about the world. In short, very often ANT is like a blasé tourist itself.

In this chapter, I take up to question of ANT's relationship to critique, not in order to point the finger at ANT, but to explore what ANT as a critical theory can accomplish. I ask with regard to which element of the world ANT is (not) critical, how and why it is so, and what the effects of this selective criticality are.

Taking up the quote by Latour cited in the beginning of this chapter, I use the metaphor of travel to do this. Travel is conceived as a mode of exploring the world (in this case the world of social science) and reporting about it, to help others to understand that world. In other words, to ask about critique means to reflexively think about the travel arrangements of ANT - how it relates to sites and practices of study, and how these travel arrangements relate to those of other travel groups, that is other groups of social scientists. In short, I suggest to look, in good ANT fashion, at the practices (and the practice of rhetorics), not the rhetorics of practice of social research (This chapter deserves to begin with a Bourdieusian rhetorical formula). 
The goals of this chapter are twofold. The first is a critique of ANT. ANT practitioners use the same travel arrangements that others use. I will thus suggest that ANT could be less blasé about its own travel arrangements. There is no basis for ANT scholars' tendency to insist on a category split between good ANT travelers and bad tourists for the sake of it; they should rather embrace the fact that all travel arrangements have complex socio-material effects that are difficult to predict and understand.

The second goal is an empirical analysis of the travel arrangements of ANT with the tools of ANT. I reconstruct the ways in which ANT practices critique and why. Given the brevity required, other versions of ANT exist that cannot be covered here.

I will first explain what I mean by critique. Then I will detail why ANT has such a dim view of critique and finally I will introduce four different kinds of critique within ANT. ANT as a critique of natural science, ANT as a non-critique of design, ANT as a critique of theories of society and finally, ANT as speculative critique of social practices. ${ }^{1}$

\section{What is critique: a primer on travel infrastructures}

The main problem of ANT seems to be that its routinized critique of critique begins with a naïve understanding of the specific properties of various kinds of travel. Like critical theory itself, it assumes that we can read from the travel devices, whether something is critique or not.

To understand the problem of critique, let me first elaborate how to conceive of the practice of critique from an ANT perspective. The most important notion of critique is Marx' "the self-clarification of the struggles and wishes of the age." (Marx 1975, 209). For ANT this is problematic, as it does not locate any agency. Luc Boltanski has helpfully summarized the notion of critique in a more compatible language: critique is based on "critical judgements on the social order which the analyst assumes responsibility for in her own name, thus abandoning any pretention to neutrality." (Boltanski 2013, 4). The "self-clarification" that Marx hints at is an actor called "analyst". As ANT scholars we might add that it is not just an analyst, but a network that takes responsibility. We could thus say that critique an arrangement that clarifies struggles by taking responsibility in the name of that arrangement, and thus abandons any pretension to neutrality.

For Boltanski, there are two additional elements that matter: First, because critique is rooted in an empirical description of a problem, it cannot make recourse to "spiritual or moral resources of a local character" (Boltanski 2013, 5). Rather, it needs to engage in a 
critique of the social order, not just some local aspect of it (saying that the sea is dirty is not critique; saying that plastic in the sea is a symptom of industrialisation is). None of this hints at an abstract definition of critique as blasé tourism.

Secondly, critique is reflexive. It needs to bring critical practice to the actors. It must "grasp the discontent of actors" and "explicitly consider them the very labour of theorization, in such a way as to alter their relationship to social reality" (Boltanski 2013, 5). From an ANT point of view, we could say that critique brings back the outcomes of scholarly research - the new world with its new connections - to those who are affected by a problem. Telling people to clean the sea up, is not critique, making the consumption of plastics difficult so that no more plastic is produced is. Again, this does not sound like blasé tourism, but rather like a complex job that requires lining up many socio-material elements.

What confuses ANT and critical theorists alike are two things. First, some seem to think that only a specific set of terms such as "capital accumulation, class, property relations, land rent, exploitation, ...." can amount to critique (Brenner, Madden, and Wachsmuth 2011, 230). Similarly, Fortun complains that the AIME platform (An Inquiry into the Modes of Existence) has no entries for terms like "asbestos", "disaster" or "petrochemicals" and therefore is not up to the job of critique (Fortun 2014, 317). But as Boltanski's work with Thévenot has shown, there are many different linguistic and material repertoires for critique, and there is no reason to restrict critique to a particular set of terms (Boltanski and Thévenot 1991).

Second, the notion of critique is overtly intentional: Critique is when someone wants to engage in acts of critique. Yet only a cursory glance at the world shows a more complex picture. Some actors engage in what they think are acts of critique, but these are roundly ignored and fail as critique, while other actors engage in practices they do not conceive of as critique, while they are understood and reacted to as if they were critique (Vikkelsø 2007). Critique, then, is a situated achievement rather than an intentional act. Equipped with these preliminaries we can have a look at the practices of ANT and how they work as critique, and what their particular travel arrangements are.

\section{Criticizing lazy travel modes by taking a budget flight: The problem of loose}

\section{translations}


If we allow for critique to be a practice that can occur in different forms and vocabularies and if we try to see what is understood in the world as critique, then we can easily see how ANT sometimes is a form of critique. ANT, so to speak, is like a tourist on a package holiday who moans about how crowded the Costa Brava is.

ANT denounces the existing practice of all other social science as wrong, because it omits the socio-material constructedness of the world from social theory (see for example Latour and Woolgar 1979; Callon and Latour 1992). More specifically, the failure of critical theory is to misunderstand the hidden, powerful "macro-actors" as hidden agents instead of as socio-material networks (see the quote at the beginning of this chapter and Callon and Latour 1981).

This critique of critique is obviously a form of critique itself: These texts do not empirically engage with the research practices of other critical social scientists. Similarly, the generic claim of ANT that all other social research does not account for material agency operates in a similar, Thomas-Cookish, way.

But why are many ANT practitioners routinely opposed to critique? Judging all travel for not being culturally and ecologically sensitive is in itself a facile move that misunderstands the cosmopolitics of travel. This obviously gets at the core of all problems of critique: How much should we denounce those in a particular situation for being in that situation, or how much should we understand their situation as being a necessity, a practice, or a position in a field? In what sense is not trying to understand a particular position already a denunciation?

At its core is the following problem: ANT (rhetorically) dislikes what I have called loose translations (Guggenheim 2015). Loose translations are translation steps that make big jumps, for example from one medium to another, or from one kind of argument to another. But for ANT, to strengthen a network means to minimize translation steps. The problem of critique is that it is based on a particularly challenging loose translation, namely the one from description to how the world could be changed, or from is to ought. For example the notion of "capitalism" operates as a loose translation that jumps from a complex socio-material arrangement to a single problematic whole. Latour identifies such loose translations with blaming "powerful agents hidden in the dark acting always consistently, continuously, relentlessly" (Latour 2004, 229). 
This loose translation is an easy target, because ANT can always point to the gap between capitalism as empirical multiplicity and problematic whole and claim that the gap is unaccounted for. But doing so is a result of its own empiricist image: it cannot imagine that a theory, qua being a theory, can make translations that do not start at the object but at the theory. ANT must always assume that critique is the worst form of laziness, of trying to insert hidden theoretical "powerful agents" as the cause for the way the world is, and the reason that the analyst cannot change the world. There is a theoretical problem here: for ANT (social) science is always translation and representation. Although it is constructivist in its self-description, the constructivism is ultimately representational. There is a gap between the empirical claim when observing scientists, that they "construct" and thereby create a world, which always contains a normative and political element, and ANT's self-description as an empirical practice that is merely descriptive. The making of the world for ANT always starts with something out there, never with something a social scientist would like to achieve.

In AIME (Latour 2013) Latour offers other ways to deal with the world, yet these are disconnected from (social) science: "fiction" is modeled on an idea of art that is unhinged from problems of the world, or "morals" is based on moral reasoning (Latour 2013). But social science as critique could be imagined as a mode that combines "fiction", "representation" and "morals", though it is neither of the three (I will later call this "speculation"). Such a social science would be precisely what focuses on the construction of the world in a triangle of what we want to achieve, a given world, and the tools we have at our disposal to do so. Before we can explore this further, let me move to another basic versions of ANT as critique.

\section{Eco-tourism with unintended consequences: ANT as critique of natural}

\section{science}

Many ANT texts, beginning with "Laboratory Life" (Latour and Woolgar 1979), manage to embark at the same time on a budget airline trip and an eco-touristic adventure (as indeed, many tourists routinely do). In the early laboratory studies ANT tried to tread as carefully as possible to not damage the local ecosystem. These studies claim to move away from a normative philosophy of science towards an empirical analysis of science as practice. By doing so, they only want the best for the locals: a more truthful account of laboratory work. Yet the whole situation descends into acrimony. The natural scientists 
see themselves misrepresented. They prefer the previous version in which they appear as heroes in search for eternal truth, rather than as muddling, politicking actors. They also claim they better know what they are doing than their observers: Witness what came to be called the science wars (Gieryn 1999; Jurdant 1998; Sokal and Bricmont 2004). In this version of critique, ANT operates in a mode of description. It claims that it only describes, that it is not a theory of the world, and that it does not critique natural science. Indeed, Latour always makes the point that he is a "lover" of natural science. ${ }^{2}$ Curiously, Latour misrecognizes the situation when he writes:

'I have rarely heard critiques of the descriptions that 'science studies' has given of scientific networks (on the contrary, the veracity of these descriptions has always been recognized [...]). And yet the alternative versions [we] have proposed ... have been hotly contested by some of the very researchers whose values we were trying to make comprehensible ... . The very words 'network' and 'fabrication' are sometimes enough to shock our interlocutors [...]. What poor diplomats we have been!” (Latour 2013, 12). For Latour, it is absolutely crucial to keep apart "the accounts the Moderns have invented [...]; the values they have held to during this same history [...]; [and] finally, my own formulation [...] of this same experience" (Latour 2013, 12).

How is it possible that a description by a lover operates as critique of his object of love? The description clashes with the self-descriptions of the objects because these selfdescriptions are informed by other theories of what these actors are doing. The scientists themselves described their own practice with a realist and positivist theory of science. The very idea that descriptions and critique can easily be kept apart ironically follows a logic of differentiation that ANT has set out to undo. Apart from the fact that many STS descriptions were indeed hotly contested by scientists (see e.g. Labinger 1995), the language of "poor diplomacy" only shows how little Latour understands his own travel arrangements. He insists on keeping descriptions and values apart, because only doing so allows for the assumption that the objects of love understand that their own accounts are wrong and those of ANT are better.

Ironically, during the science wars, the opponents of ANT and STS did not bother to keep critical accounts, say the feminist versions of Donna Haraway and Evelyn Fox Keller, apart from those of the purported lovers. The opponents even failed to spot that feminist scholars explicitly criticized ANT for their supposedly uncritical accounts. What mattered for the scientists was that they felt misrepresented. 
To sum up, what critique is, and whether it succeeds in the unavoidably reflexive encounters with its object, is demonstrably not a quality of the intentions, nor the labeling of a scientific theory or approach, but of the encounter with its object. ANT practitioners in this second version are like tourists who buy eco-friendly trips to animal reserves and are surprised if the locals who live everyday with the animals neither approve of the photographs that are taken of them, nor of the advice to let the animals roam free.

\section{The spa-holiday: ANT as a (non-)critique of Architecture and design}

While the relationship with science has been strained, ANT has had much better relationships with other objects of inquiry, most notably architecture and design (for example Latour has written a regular column for Domus, one of the main architecture magazines, and architects such as Alejandro Zaero Polo, Andres Jaque or Nerea Calvillo have embraced it). The identical practice of describing socio-material practices has resulted in the case of science in the vigorous objection of those described and in the case of design in an enthusiastic embrace.

The travel destination matters to how the relations with the locals pan out. The problem is not necessarily the mode of travel, but how the travel mode fits local infrastructures. Spa holidays are increasingly popular (I like them too): You don't venture very far, but do it with the least amount of trouble: everyone is nice to you. Afterwards, the spa hotel publishes your praise on their website and your words look very much like theirs. Structurally, this second version operates very much like the first: it uses the description of a practice to formulate a critique of social science. The empirical description of building and design practices serves to critique other social science as ignoring the ongoing recomposition of socio-material arrangements at the expense of semiotic or structural analysis. The difference between science and design is that in the case of the latter, the attribution of agency to designers and the notion of "fabrication" and "construction" to describe their work perfectly fits their self-description. This is unlike scientists, who abhor the idea that objects in the world are connected to their own agency. When Latour alleges that "when we try to reconnect scientific objects with $[\ldots]$ their web of associations, [...] we always appear to weaken them, not to strengthen their claim to reality." (Latour 2004, 237), then this only holds for scientific objects. For design objects, the opposite is true, as can be gathered from any 
architect's description of her project. There are thus no critical effects of ANT descriptions of architecture. The reason is not that ANT practitioners fail to be critical, but because the very same methods and theories that have critical effects in one field fail to do so in a different field. ANT scholars end up on spa holidays not because they chose that destination, but because their hosts like their travel accounts.

\section{Executive Business Travel: ANT as modes of existence}

"Our flight must take place above the clouds, and we must reckon with a rather thick cloud cover. We must rely on our instruments. Occasionally, we may catch glimpses below of a land ... that remind us of something familiar, or glimpses ... of landscape with the extinct volcanoes of Marxism. But no one should fall victim to the illusion that these few points of reference are sufficient to guide our flight. " (Luhmann 1995, l)

Even ANT practitioners sometimes feel the need to fly above the clouds. Getting somewhere far away means that we cannot stop in every village and try to understand how it is different from the one next to it. Hence our reports afterwards are more concerned with talking about the quality of different airlines and whether the connections at the airports worked, rather than the actual destinations. Such business travel needs to be taken seriously as a practice, even though most travelers are routinely dismissive of it as a second-hand experience of non-spaces. Bruno Latour in particular has, in his second career as "philosopher" (Latour 2010)3 made a business of exploring new airlines and rarely visited airports. Like Luhmann, he prefers to bypass the extinct volcanoes.

ANT as a theory of modes of existence is a full-on critique of "modernity" (Latour 1993, 2013). Modernity here means the way we - which is everyone who uses a vocabulary that refers to items such as "science", "politics", the "environment" etc. - understand our world.

For Latour the fundamental mistake of modernity is not that it has destroyed the world or brings injustice (as critical theorists would have it), but that the way we conceive of how anything comes into existence is misguided. As with Luhmann, the main point for Latour is that by flying high enough, we learn to avoid prioritizing one mode, learn to give justice to each mode, and "learn to respect appearances", based on the central notion of "felicity condition": This is the idea that there are specific ways how each 
mode operates and that it is fundamentally futile to overextend this mode as long as we operate within it.

"Modes of existence" (MoE) is thus a large-scale critique of all other ways of understanding and critiquing modernity that fail to understand the operation of each mode of existence. Hence Latour's self-designed tests of whether the theory of MoE succeeds is based on how it respects each mode: "does the detection of one mode allow us to respect the other modes? ... Can the inquiry mutate into a diplomatic arrangement ... while a new space is opened up for comparative anthropology by a series of negotiations over values?” (Latour 2013, 475).

The enemy of all these tests are theories that are attached to a single mode, such as the existing philosophy of science, theology, sociology of culture etc. According to Latour, these all fail, first, because they are not based on ethnographic inquiry and second because they reduce it to some element that does not correspond to the self-description of the field.

The notion of "ideology" in critical theory describes something very similar: the fact that the self-description of the world by existing mode-specific theories is wrong. For "critical" theory, the wrongness of ideology derives from the fact that actors try to obscure the "real" working of these modes in order to exert power over those who do not see behind ideology. Ideology justifies a practice that is wrong.

For Latour, there is nothing wrong with practices, only with descriptions of practices. ${ }^{4}$ Thus, the descriptions of Marxists and economists, of philosophers of science and Marxist critics of science etc. are equally wrong, because they do not match the empirical complexity of the world. One irony of this approach is that it forgets that philosophy (of science, the economy etc.) is also a practice. It is not clear why it should not also be taken seriously as empirical phenomenon and thus given the status of being "right" like any other practice.

One important question then is why practices should always be right, and never objects of critique, while theoretical descriptions should be critiqued and are almost all wrong. Crucially, here Latour's critique mirrors the Marxist critique: The standard for critique is pre-given by the theory: in the case of Marxists, ideology is always with the others, who are deemed to veil the capitalist system. In the case of $\mathrm{MoE}$, it is always the theories that veil the logic of MoE. Another irony then is why a theory that purports to take local practices seriously does not allow itself to suggest how such local practices could be critiqued, changed and improved? Taking practices seriously in their empirical complexity 
surely entails to suggest that some practices are better than others, once we agree on what these practices are supposed to do? A more refined program, and one probably far more in line with the intention of the author would be to ask how and why descriptions match or do not match practices?

\section{The exchange student: ANT as incubation and speculation}

When you are young, you want to go abroad to learn, and you stay with a family whose internal dynamics will become equally perturbed as your own life by this experimental cohabitation in the name of cultural exchange.

In ANT there are a number of projects and practices that come variously under the rubric speculation (Wilkie, Rosengarten, and Savransky 2016), inventiveness (Lury and Wakeford 2011) or, our own, incubation (Guggenheim, Kräftner, and Kröll 2017). There are important differences between these approaches, but they all begin with the typical focus of ANT approaches on socio-material entities, "a criticality that is oriented towards tracing the complex messy entanglements of societies with all their strange, weird and wonderful hybrid objects" (Ward and Wilkie, 2009: 2). But this empirical outlook is not guided towards a critique of theories, but towards an experimental modification of practices with the help of various devices. Unlike in critical social science, speculative practitioners to not denounce practices, nor do they try to change practices according to a given theoretical standard. Rather, inventive or speculative methods are employed to change the world in unforeseen directions. They begin with the insight that in moments of controversy the social world is performatively opened up. This "moment of dispute" is also recognized by Boltanski as a possible moment of critique, "when actors express their moral claims ... they 'perform' the social in an innovative way." (Boltanski 2013, 12).

But rather than simply analyzing such moments, inventive methods aim to create such situations. Like the student on a gap year, they jump head on into an unforeseen situation. Many of these methods derive not only from social science, but take their leads from scientific experiments, design or arts practices. The reason for these choices is that the latter have a history of self-consciously interfering with socio-material devices into the world. ANT could have learnt this from its own analysis of such practices, but too often this has not happened.

Such inventive methods become tools of critique, because they allow ANT practitioners to intervene in practices by giving actors in the field the resources at hand to clarify and 
change their situation. But at the same time, this does not happen with a participatory naivety, in which the social scientists already know what is wrong, what should be achieved, or even how anything could be achieved. Rather, a methodological, theoretical and material repertoire is employed in unforeseen ways. Just like the effects of having an exchange student in your house, such work is highly risky, and may be contested by the locals. It does not necessarily play to easy forms of "participation" in which local practices are taken as standards. Rather, it brings strategic devices that are strange to the locals to create new situations that have not existed before.

\section{Returning Home}

After this extensive tour of travel modes, we can now answer the question "What about critique?" in a rather straightforward way. First, as I have shown, ANT should be a little bit less blasé about its own travel arrangements. There are reasons why people take cheap flights and ANT practitioners sometimes do so too, for the same reasons. Sometimes, the goal is to quickly get somewhere, as we have seen in the version of ANT as critique of social science and modes of existence. Sometimes, eco-tourism inadvertently turns into a mess, as we have seen in the attempts of ANT to be sympathetic, descriptive and non-critical towards science. Critique, in these cases is not a matter of intention, but of reception. Finally, ANT can also be a practice of creating situations in which actors can open up and re-compose the world. This mode though forces us to give up both the radical empiricism of ANT as well as the stance that we know how to change the world. We then need to engage in a radical encounter with the world in which we accept and embrace our practice as intervention, without knowing where it will end up.

\section{Bibliography}

Boltanski, Luc. 2013. On Critique: A Sociology of Emancipation. Oxford: Wiley. Boltanski, Luc, and Laurent Thévenot. 1991. De La Justification. Les Economies de La Grandeur. Paris: Gallimard.

Brenner, Neil, David J. Madden, and David Wachsmuth. 2011. 'Assemblage Urbanism and the Challenges of Critical Urban Theory'. City 15 (2): 225-40. https://doi.org/10.1080/13604813.2011.568717.

Callon, Michel, and Bruno Latour. 1981. 'Unscrewing the Big Leviathan: How Actors Macrostructure Reality and How Sociologists Help Them to Do So'. In Advances in Social Theory and Methodology: Toward an Integration of Micro- and Macro-Sociologies, edited by Karin Knorr-Cetina and Aron Cicourel, 277-303. Boston: Routledge. 
1992. 'Don't Throw the Baby Out With the Bath School! A Reply to Collins and Yearley'. In Science as Practice and Culture, edited by Andrew Pickering, 343-68.

Chicago: Chicago University Press.

Fortun, Kim. 2014. 'From Latour to Late Industrialism'. HAU: Journal of Ethnographic Theory 4 (1): 309-329.

Gieryn, Thomas. 1999. 'Home to Roost: Science Wars as Boundary Work'. In Cultural Boundaries of Science. Credibility on the Line, edited by Thomas Gieryn, 336-62. Chicago: Chicago University Press.

Guggenheim, Michael. 2015. 'The Media of Sociology: Tight or Loose Translations?' British Journal of Sociology 67 (June): 345-72.

Guggenheim, Michael, Bernd Kräftner, and Judith Kröll. 2017. 'Incubations: Inventing Preventive Assemblages'. In Inventing the Social, edited by Noortje Marres, Michael Guggenheim, and Alex Wilkie. Manchester: Mattering Press.

Jurdant, Baudouin, ed. 1998. Impostures Scientifiques. Les Malentendus de l'Affaire Sokal. Paris: La Découverte.

Labinger, Jay A. 1995. 'Science as Culture. A View from the Petri Dish'. Social Studies of Science 25: 285-306.

Latour, Bruno. 1993. We Have Never Been Modern. Cambridge: Harvard University Press. 1996. Der Berliner Schlïssel. Erkundungen Eines Liebhabers Der Wissenschaften. Berlin: Akademie.

. 2004. 'Why Has Critique Run out of Steam? From Matters of Fact to Matters of Concern'. Critical Inquiry 30 (Winter): 226-48.

. 2010. 'Coming Out as a Philosopher'. Social Studies of Science, 599-608. https://doi.org/10.1177/0306312710367697. . 2013. An Inquiry into Modes of Existence: An Anthropology of the Moderns. Cambridge Mass.: Harvard University Press.

Latour, Bruno, and Steve Woolgar. 1979. Laboratory Life. The Social Construction of Scientific Facts. London/Thousand Oaks/New Delhi: Sage.

Law, John. 2008. 'On Sociology and STS'. The Sociological Review 56 (4): 623-49. https://doi.org/10.1111/j.1467-954X.2008.00808.x.

Luhmann, Niklas. 1995. Social Systems. Writing Science. Stanford, Calif.: Stanford University Press.

Lury, Celia, and Nina Wakeford, eds. 2011. Inventive Methods: The Happening of the Social. London: Routledge.

Marx, Karl. 1975. 'Letter to A. Ruge, September 1843'. In Early Writings, translated by Rodney Lingstone and Gregor Benton, 209. New York: Vintage.

Sokal, Alan D, and J Bricmont. 2004. Intellectual impostures: postmodern philosophers' abuse of science. London: Profile Books.

Vikkelsø, Signe. 2007. 'Description as Intervention: Engagement and Resistance in Actor-Network Analyses.' Science as Culture 16 (3): 297-309. https://doi.org/10.1080/09505430701568701.

Wilkie, Alex, Marsha Rosengarten, and Martin Savransky, eds. 2016. Speculative Research: The Lure of Possible Futures. London: Routledge.

\footnotetext{
${ }^{1}$ This basic logic of this chapter shares many similarities with the chapters by Daniel López and José Ossandon in this volume, though each of us focuses on a different analytical plane.

${ }^{2}$ Latour's first German book is subtitled "investigations of a lover of the sciences" (Latour 1996).
} 
${ }^{3}$ It is notable that in Latours self-understanding as an Anglo-French STS/sociologist/anthropologist, business travel as writing the „Modes of Existence” equals philosophy. For Luhmann, writing in the provinces of Germany, flying above the clouds is easily compatible with sociology.

${ }^{4}$ Muniesa follows this route when considering ANT as critique of capital in this volume. 